\title{
Blood oxygen level dependent and adenosine- perfusion imaging correlates to invasive measurement of fractional flow reserve
}

\author{
Peter Bernhardt ${ }^{1 *}$, Robert Manzke ${ }^{2}$, Thomas Walcher ${ }^{1}$, Wolfgang Rottbauer ${ }^{1}$ \\ From 15th Annual SCMR Scientific Sessions \\ Orlando, FL, USA. 2-5 February 2012
}

\section{Background}

It has been shown that blood oxygen level dependent (BOLD) cardiac magnetic resonance imaging (CMR) is able to detect myocardial perfusion differences. However, validation of BOLD CMR against myocardial perfusion reserve (MPR) and fractional flow reserve (FFR) is lacking. We sought to analyze the potential diagnostic accuracy of BOLD CMR in comparison to invasively measured FFR which served as the standard reference.

\section{Methods}

BOLD and contrast-enhanced perfusion image analyses were performed at rest and during adenosine infusion in a 1.5T CMR scanner in three short axes (apical, midventricular and basal), respectively. Thirty-six perfusion territories in twelve patients were analyzed for relative BOLD signal intensity increase and for myocardial perfusion reserve. In all patients invasive FFR measurements were performed in the major three coronary arteries during adenosine infusion. A FFR $\leq 0.8$ was regarded consistent with significant hypoperfusion.

\section{Results}

Relative BOLD signal intensity increase was significantly higher in myocardial segments supplied by coronary arteries with a FFR $\leq 0.8(\mathrm{p}<0.05)$. The area under the receiver operator curve for BOLD and MPR analysis did not differ significantly for segments perfused by the left anterior descending artery ( 0.80 vs. 0.73$)$, left circumflex artery $(0.80$ vs. 0.98$)$ and right coronary artery ( 0.97 vs. $0.97)$.

${ }^{1}$ University of Ulm, Ulm, Germany

Full list of author information is available at the end of the article

\section{Conclusions}

CMR BOLD imaging reliably detects hemodynamic significant coronary artery disease and is an alternative to contrast-enhanced perfusion without use of exogenous contrast agents.

\section{Funding}

None.

\section{Author details}

'University of Ulm, Ulm, Germany. ${ }^{2}$ Philips Clinical Sites Research Europe,

Hamburg, Germany.

Published: 1 February 2012

doi:10.1186/1532-429X-14-S1-P300

Cite this article as: Bernhardt et al:: Blood oxygen level dependent and adenosine-perfusion imaging correlates to invasive measurement of fractional flow reserve. Journal of Cardiovascular Magnetic Resonance 2012 14(Suppl 1):P300.

Submit your next manuscript to BioMed Central and take full advantage of:

- Convenient online submission

- Thorough peer review

- No space constraints or color figure charges

- Immediate publication on acceptance

- Inclusion in PubMed, CAS, Scopus and Google Scholar

- Research which is freely available for redistribution

\section{() Biomed Central}

(c) 2012 Bernhardt et al; licensee BioMed Central Ltd. This is an open access article distributed under the terms of the Creative Commons Attribution License (http://creativecommons.org/licenses/by/2.0), which permits unrestricted use, distribution, and reproduction in any medium, provided the original work is properly cited. 